\title{
"Parece que isso foi de verdade. Realmente Dom Pedro teve uma amante"1: performances de gênero em narrativas midiáticas sobre Pedro I e Leopoldina
}

\author{
Jarlene Rodrigues REIS ${ }^{2}$ \\ Denise Costa Oliveira SIQUEIRA ${ }^{3}$
}

Resumo:

O objetivo do trabalho é compreender de que forma se manifestam, nas representações midiáticas de Dona Leopoldina de Habsburgo e Dom Pedro I, performances ligadas aos gêneros feminino e masculino. Construídos a partir de indicativos de gênero que marcam a dicotomia feminino x masculino, os personagens que representam o casal demonstram mudanças nas relações e nos significados sociais dos papeis de gênero ao longo do tempo. A partir do filme Independência ou Morte e da telenovela Novo Mundo, reflete-se sobre como as narrativas de gênero envolvendo o casal de monarcas contribuem para a produção de sentidos sobre os papéis de mulheres e de homens na sociedade brasileira. Leituras sobre a construção social dos gêneros fundamentam a discussão, que articula referenciais da História e das Ciências Sociais.

Palavras-chave: performances de gênero; Independência ou Morte; Novo Mundo; Dom Pedro I; Leopoldina de Habsburgo.

\section{"I think this was for real. Dom Pedro really had a lover": gender performances in media narratives about Pedro I of Brazil and Leopoldine of Habsbourg}

\begin{abstract}
:
The aim of this study is to understand how media representations of Dona Leopoldine of Habsbourg and Dom Pedro I of Brazil reproduce gender performances socially associated to woman and man. Constructed from gender indications that highlight the female/male dichotomy, the characters that represent the couple lead us to know the changes in the relationships and social meanings of gender roles over time. From the film Independência ou Morte and the soap opera Novo Mundo, it reflects on how gender narratives concerning the couple of monarchs contribute to the production of meanings about the roles of women and men in Brazilian society. References on the social construction of genders underlie the discussion, which articulates readings from the fields of History and Social Sciences.
\end{abstract}

\footnotetext{
${ }^{1}$ Comentário de usuária no YouTube (NOVO MUNDO..., 2017).

${ }^{2}$ Doutora em Comunicação pelo Programa de Pós-Graduação em Comunicação Social da Universidade do Estado do Rio de Janeiro (PPGCOM/UERJ), com estágio de pesquisa no Institut d'Histoire du Temps Présent da Université Paris VIII. Professora do Centro Federal de Educação Tecnológica Celso Suckow da Fonseca (CEFET/RJ), campus Petrópolis. E-mail: jarlene.reis@ cefet-rj.br.
}

${ }^{3}$ Doutora em Ciências da Comunicação pela Universidade de São Paulo (USP). Desenvolveu pesquisa pósdoutoral em Sociologia na Université Paris-Descartes/Sorbonne. Professora Titular da Faculdade de Comunicação da Universidade do Estado do Rio de Janeiro (UERJ).E-mail: dcos@uerj.br. 
Keywords: Gender performances; Independência ou Morte; Novo Mundo; Pedro I of Brazil; Leopoldine of Habsbourg.

\title{
"Parece que eso fue de verdad. Don Pedro realmente tenía un amante": performances de género en las narrativas de los medios sobre Pedro I de Brasil y Leopoldina de Austria
}

\begin{abstract}
Resumen:
El objetivo del trabajo es comprender cómo, en las representaciones mediáticas de Doña Leopoldina de Austria y Don Pedro I de Brasil, se manifiestan performances relacionadas con los géneros masculino y femenino. Construidos a partir de características de género asociadas con la dicotomía femenino x masculino, los personajes que representan la pareja demuestran cambios en las relaciones y en los significados sociales de género a lo largo del tiempo. Basado en la película Independencia o Muerte y la telenovela Nuevo Mundo, se discute cómo las narrativas de género que involucran a la pareja monarca contribuyen a la producción de significados sobre los roles de mujeres y hombres en la sociedad brasileña. Lecturas sobre la construcción social de géneros apoyan la discusión, que reúne referencias de la Historia y las Ciencias Sociales.
\end{abstract}

Palabras clave: Performances de género; Independencia o Muerte; Nuevo Mundo; Pedro I de Brasil; Leopoldina de Austria.

\section{Introdução}

Desde o início da pandemia do coronavírus, no primeiro semestre de 2020, as mídias têm desempenhado importante papel na organização da dinâmica social configurada em razão das medidas de distanciamento físico e isolamento. A televisão, seja por meio de sua programação convencional ou por meio de plataformas de streaming, ofereceu informação e entretenimento a um público ávido por ocupar o tempo durante a "quarentena", especialmente durante os primeiros meses da pandemia. No Brasil, a Rede Globo de Televisão exibiu diversas reprises de telenovelas, em virtude da suspensão das gravações de produções inéditas.

Novo Mundo, novela veiculada em 2017, pela Rede Globo, voltou ao ar no horário das 18h, substituindo Nos tempos do Imperador, cuja estreia estava prevista para o dia 20 de março mas precisou ser adiada devido à pandemia. Esta última, idealizada pelos mesmos autores de Novo Mundo, seria uma espécie de continuação da trama que foi sucesso em 2017 - Nos tempos do Imperador traria como protagonista Dom Pedro II, filho de dois importantes personagens da produção anterior. Portanto, a reprise de Novo Mundo atendia ao mesmo público interessado por romances históricos, pois sua trama era ambientada durante o período da Independência do Brasil, com Dona Leopoldina de Habsburgo e Dom Pedro I entre os personagens principais. Construídos a partir de indicativos de gênero que marcam uma dicotomia feminino e masculino, 
os personagens de Leopoldina e Pedro chamam a atenção para o desenvolvimento das narrativas audiovisuais sobre o casal nas últimas décadas, desde o filme Independência ou Morte, primeira produção ficcional brasileira a retratá-los, na década de 1970.

No Brasil, a imagem de uma cultura considerada festiva divide espaço com o conservadorismo de parcelas da sociedade. Os preconceitos daí decorrentes produzem índices alarmantes de violência contra as mulheres e a população LGBTQIA+. ${ }^{4}$ As representações dos papéis de gênero nas produções audiovisuais nem sempre refletem a complexidade dessas construções identitárias - embora nas primeiras décadas do século XXI venham ganhando espaço novas abordagens a partir da interseccionalidade entre gênero e raça (MACHADO, 2017).

A teledramaturgia nacional, que tem na telenovela seu principal-representante, ainda privilegia contextos e espaços atribuídos à condição feminina, como o ambiente familiar (HAMBURGER, 2011). Não obstante, nas novelas também são expressos elementos que compõem o universo e a construção da masculinidade (JAKUBASZKO, 2014). Representações femininas e masculinas em tela refletem e se refletem em comportamentos e práticas sociais. Quando se trata de produções com inspiração histórica, personagens emblemáticos agregam ainda mais significado a essas representações, devido a seu relevo no imaginário coletivo. É o caso de Dom Pedro I e de Dona Leopoldina de Habsburgo.

Entendendo que nas produções audiovisuais de inspiração histórica os personagens são construídos conforme perspectivas e intenções dos realizadores, observa-se que ao mesmo tempo em que se busca amparo na historiografia, encontram-se representações ligadas a estereótipos de aparência e de comportamento (FONSECA, 2018). As narrativas midiáticas ecoam imaginários que sintetizam papéis atribuídos a mulheres e homens em filmes, telenovelas, documentários.

Em tais produções, os elementos de caracterização de Pedro e Leopoldina fazem menção frequente às suas posições de gênero, demarcadas por seus papéis como "marido e esposa",

\footnotetext{
${ }^{4}$ O Brasil foi classificado pela Organização Mundial da Saúde como o $5^{\circ}$ país com maior número de feminicídios no mundo. A violência homofóbica também produz números alarmantes, como demonstram dados da Associação Nacional de Travestis e Transexuais (s.d.) e Joyce Ribeiro (2019).
} 
“imperador e imperatriz". Nesse contexto, delimita-se a condição masculina de Dom Pedro I e a feminina de Dona Leopoldina e as performances daí derivadas, culturalmente associadas a ser homem ou mulher.

Em 1972, o filme Independência ou Morte apresentava Tarcísio Meira como protagonista, na pele do primeiro imperador do Brasil. Encontram-se ali os sinais do que tornarse-ia, nas representações midiáticas ficcionais, a "marca" de Dom Pedro I, interpretado por um dos galãs da teledramaturgia nacional. Kate Hansen encarnou a imperatriz Leopoldina, em caracterização que reproduziu aspectos reconhecidos da primeira esposa de Pedro.

Independência ou Morte, lançado no ano das comemorações do Sesquicentenário da Independência, foi o primeiro filme não documental brasileiro a retratar, como personagens, Leopoldina e Pedro. Nas décadas seguintes, o casal surgiu na série Marquesa de Santos, transmitida em 1984 pela Rede Manchete; na minissérie $O$ quinto dos infernos, produção da Rede Globo, de 2002; e na telenovela Novo Mundo.

Nessas obras, a união entre Leopoldina e Pedro I ganhou visibilidade a partir de seu papel na história do país. Reconhecidos como articuladores do processo de Independência, eles inspiraram uma variedade de narrativas e representações, tanto na historiografia quanto em obras audiovisuais de ficção (REIS; SIQUEIRA; MENDES, 2018).

A relevância histórica das duas personalidades faz com que suas representações assumam caráter emblemático no tocante aos aspectos que determinam suas performances de gênero. Nessa ótica, a posição de Pedro e Leopoldina como "exemplos" ou "modelos" parece explícita em virtude de sua participação não apenas nos desdobramentos que levaram à Independência do Brasil, como também na introdução de elementos que compõem o que se considera como uma “identidade nacional” (RIBEIRO, A., 2005, p. 8).

A discussão que propomos neste trabalho é derivada das reflexões sobre os indicativos de gênero nas caracterizações de Pedro e Leopoldina em suas representações midiáticas ficcionais. O problema de pesquisa pode ser resumido na questão: de que forma se manifestam, nas representações midiáticas de Dona Leopoldina de Habsburgo e Dom Pedro I, performances ligadas às delimitações dos gêneros feminino e masculino?

Estudamos a mais antiga e a mais recente produções audiovisuais que retratam o casal, a fim de obter uma visão comparativa sobre os modos como se fabricam narrativas de gênero 
envolvendo os primeiros monarcas do Brasil. O filme Independência ou Morte, dirigido por Carlos Coimbra, e a telenovela Novo Mundo, de Thereza Falcão e Alessandro Marson, compõem o material investigado. O objetivo consiste em identificar performances e elementos de caracterização do feminino e do masculino nos personagens que representam Dona Leopoldina e Dom Pedro I.

O embasamento teórico para a pesquisa reúne leituras sobre a construção social dos sentidos de gênero feminino e masculino tanto na perspectiva da História quanto no olhar das Ciências Sociais, a partir de obras de autores como Simone de Beauvoir (1949), Judith Butler (1999), Michelle Perrot (1989;1995; 1997), Alain Corbin, Jean-Jacques Courtine e Georges Vigarello (2011), Nadia Tazi (2018), Armelle Enders (2012) e Denise Siqueira (2017).

Entender o modo como se produzem narrativas sobre gênero no Brasil em torno de personalidades históricas é fundamental para que se compreendam os mecanismos que operam, na contemporaneidade, imaginários e interpretações ligadas aos papéis de homens, mulheres e outros gêneros.

\section{Papéis feminino e masculino no poder}

O binarismo reducionista feminino x masculino está no cerne de representações de gênero nas mídias audiovisuais. Para compreendê-lo, é necessário recorrer a perspectivas teóricas que questionam essa dicotomia, trazendo à tona elementos culturais, históricos e sociais que concorrem para a delimitação dos papéis sociais de mulheres e homens.

O conceito de gênero tem origem na busca por uma visão historicamente situada e não determinista das categorias "homem" e "mulher", enfatizando um sistema de relações que não inclui somente as diferenças sexuais, mas sobretudo as relações políticas e de poder (SCOTT, 1986; BUTLER, 1999). Enquanto o gênero masculino representa uma identidade universal, o sujeito histórico padrão, a noção de mulher tem sido relacionada ao "outro", complementar ao homem. O "segundo sexo", alcunha consagrada por Beauvoir (1949), afirma-se em confirmação às pretensões e expectativas masculinas. Vista dessa forma, a ideia de "feminino" se constrói culturalmente a partir de sua relação com o masculino, entendido como o parâmetro de neutralidade e de universalidade. 
Ampliando a discussão para entender como se constroem os sentidos ligados ao gênero, Lauretis (1994, p. 228) destaca o papel do que nomeia como "tecnologias do gênero", que incluem o cinema e outras estruturas narrativas produtoras de significados. Social e midiaticamente, representações do feminino se ancoram em referenciais androcêntricos, assinala a autora. Os padrões associados ao gênero masculino se refletem na sub-representação nas artes e na cultura, reduzindo personagens femininas a estereótipos ou ao papel de coadjuvantes (MENDES; SIQUEIRA, 2018).

Quando se trata de mulheres em posições de poder, contudo, há uma certa aceitação social para que elas exerçam importantes papéis, não obstante sua condição feminina. Em virtude dessa distinção, rainhas e regentes puderam atuar com destaque em momentos da história (BEAUVOIR, 1949). No entanto, às mulheres casadas com monarcas ou presidentes coube um papel protocolar. Delas se esperam habilidades sociais, artísticas e caritativas, um papel complementar, ornamental à função oficial exercida pelo esposo (SOLNON, 2012).

No Brasil republicano, pelo menos desde a década de 1940, o trabalho das primeirasdamas tem sido utilizado como forma de sustentação política para seus maridos, a partir da apropriação de atributos considerados femininos, como bondade, amor e doação (TORRES, 2002). Entretanto, também no período do Brasil imperial, encontram-se traços de um imaginário que valorizava, em imperatrizes e princesas, as características que ainda hoje se associam aos papéis femininos. Assim se registrou, em relatos, a imagem de Leopoldina de Habsburgo como esposa dedicada, "um padrão para a mulher brasileira", em razão de sua singeleza e de seu nobre comportamento (OBERACKER JR., 1973, p. 143).

A demarcação cultural de papéis tem sido caracterizada pela atribuição dos espaços e funções públicas aos homens, enquanto os lugares privados são entendidos como a esfera de domínio feminino. Daí se origina certa invisibilidade histórica feminina que, segundo Perrot (1989), deve-se também às dinâmicas de arquivo e registro que privilegiam a dimensão pública. A vida privada e cotidiana, domínio consagrado às mulheres, é objeto de uma espécie de encobrimento nos registros históricos, fruto tanto da predominância masculina nos acontecimentos públicos quanto das formas de elaboração dos relatos (PERROT, 1995).

Torres (2002) assinala que o modo como homens e mulheres se percebem é fruto de construções históricas que dependem dos regimes de verdade de cada sociedade, gerando 
identificações relacionadas às expectativas de comportamento que se atribuem, coletivamente, à estrutura binária de gêneros feminino x masculino. Nas esferas de poder ainda se entende que a política seja uma função essencialmente masculina, uma profissão de homens, como ressalta Perrot (1997). Ainda hoje, às cônjuges dos governantes cabe o exercício do "primeirodamismo", marcado principalmente por atividades de filantropia e assistência social não institucionalizadas como funções oficiais (LOPES; GROSSI, 2019).

Já o poder masculino é discursivamente naturalizado por meio da ideia de virilidade comumente associada a posições de liderança. Como pondera Tazi (2018), a constituição de nações se fundamenta, muitas vezes, em lendas e epopeias ilustradas pela virilidade de conquistadores e figuras que inspiram ideários mitificados. Nessa perspectiva, Corbin, Courtine e Vigarello (2011) entendem a virilidade como um termo que carrega um conjunto de qualidades que compreendem um modelo de força, virtude, segurança, maturidade e controle. Para os mesmos autores, o ideal viril está em constante transformação, conforme as práticas sociais e culturais de cada tempo. A virilidade é construída historicamente no seio de práticas e socialidades cotidianas (CORBIN; COURTINE; VIGARELLO, 2011).

Ligada à figura do chefe (da família, do Estado ou de outras esferas de organização social), a virilidade não consiste em simples maximização do masculino, mas sobretudo de algo politicamente instituído (TAZI, 2018). Ainda para Tazi (2018), ao mesmo tempo que o sujeito viril se pretende único e original, oculta falhas e angústias que podem ameaçar sua imagem. Como também assinalam Corbin, Courtine e Vigarello (2011), a inquietação gerada pelas próprias fragilidades plana sobre a excelência exigida pelos pressupostos de virilidade.

O binarismo das demarcações identitárias de gênero faz com que, mesmo entre as mulheres que exerceram ou exercem funções máximas de poder, busquem-se assinalar aspectos que as aproximem de características consideradas masculinas. Assim teria dito, modestamente, a imperatriz Maria Teresa da Áustria (durante quarenta anos imperatriz do Sacro Império Romano-Germânico): "Sou apenas uma mulher, mas tenho o coração de um rei” (SOLNON, 2012, p. 8, tradução nossa). ${ }^{5}$ Como se as mulheres, uma vez em função de poder, ali estivessem de forma deslocada e provisória.

\footnotetext{
${ }^{5}$ No original: “Je ne suis qu'une femme, mais j'ai le cœur d'un roi” (SOLNON, 2012, p. 8).
} 


\section{Para além de príncipe e princesa: performances de gênero na mídia}

As tensões atualmente manifestadas em diversas esferas de discussão social no Brasil no que concerne aos papéis de gênero demonstram a dimensão da importância e dos conflitos suscitados por essa pauta. Jornais, mídias sociais e produções audiovisuais ecoam debates sobre os atributos socialmente associados a homens e mulheres, invisibilizando outros papéis de gênero. 6

De modo geral, o cenário midiático brasileiro (re)produz narrativas em que a sensualidade e o corpo determinam a presença e a atuação social feminina. A postura assertiva e desafiadora de cantoras como Anitta e Valeska Popozuda faz com que se destaquem como "divas", mulheres empoderadas por meio de suas performances corporais (dança, maquiagem, indumentária, intervenções estéticas) e midiáticas (o alcance e as interações geradas por seus videoclipes na internet refletem seu sucesso). Esse poder midiático, entretanto, não se reflete em instâncias políticas de decisão e de mudança social (SIQUEIRA, 2017).

A imagem das divas poderosas do pop se contrapõe à ideia de fragilidade feminina, associada a uma concepção a-histórica das diferenças físicas entre mulheres e homens (BEAUVOIR, 1949). Essa fragilidade, determinada mais por referenciais culturais do que biológicos, revela-se em representações de personagens femininas em produções audiovisuais. É a partir dessas referências que se constroem representações femininas no cinema brasileiro, desde a jovem inocente até a prostituta, reproduzindo valores patriarcais (GUBERNIKOFF, 2009). Mulheres poderosas como mulheres frágeis das representações midiáticas se encontram sujeitas a perspectivas limitantes que privilegiam a condição masculina.

Em produções midiáticas que retratam episódios históricos, as abordagens dos papéis de gênero se baseiam tanto no contexto social e histórico em que as obras são realizadas, como nas pesquisas feitas durante a elaboração dos roteiros. Os personagens "históricos" inscrevemse no repertório coletivo, congregando elementos que articulam poderes políticos, feitos

\footnotetext{
${ }^{6}$ Em 3/01/2019, após tomar posse à frente do Ministério da Mulher, Família e Direitos Humanos no Brasil, Damares Alves proferiu a frase polêmica: "Atenção, atenção! É uma nova era no Brasil, meninos vestem azul e meninas vestem rosa!". A fala, projetada nas esferas midiática e social, reavivou discussões sobre o que se consideram, no Brasil, os indicativos de gênero (DECLARACÃO..., 2019).
} 
individuais e adesão popular. Seu potencial para mobilizar emoções coletivas é o que os transforma em heróis, vultos nacionais (ENDERS, 2012).

Ao representar midiaticamente a história, filmes e telenovelas operam na produção de sentidos, integrando um tipo de cultura histórica moldada pelos discursos midiáticos, cuja intensidade influencia de forma decisiva as imagens que guardamos do passado (LANDSBERG, 2015). No Brasil, essa cultura reflete, na mídia, as visões lineares e tradicionais (reconhecidas como "oficiais") da historiografia (FONSECA, 2016). Pinturas, documentários, filmes e produções televisivas seguem, muitas vezes, representações recorrentes de grandes acontecimentos e personalidades, repetindo e reforçando temáticas já conhecidas.

Dentre as produções que retratam a Independência do Brasil, destaca-se o longametragem Independência ou Morte, lançado em meio às comemorações dos 150 anos da Independência do Brasil, durante o período mais repressivo da ditadura militar. Considerado oficialista por críticos da época, o filme teve grande alcance, alinhando-se às estratégias publicitárias do governo do presidente Ernesto Garrastazu Médici e tendo sido considerado pela presidência como "exemplo a ser seguido" (MARCELO, 2011, não paginado). Na produção, celebra-se de forma especial a figura de Dom Pedro I, considerado herói da Independência.

A produção mais recente a retratar Pedro e Leopoldina como personagens foi a telenovela Novo Mundo, exibida pela Rede Globo entre março e setembro de 2017. A trama foi ambientada na cidade do Rio de Janeiro, do período anterior à proclamação da Independência até o início da consolidação do novo Império no país. $\mathrm{O}$ arco narrativo principal se passa em torno do casal Anna Millmann (interpretada por Isabelle Drumond) e Joaquim Martinho (interpretado por Chay Suede). Os dois viajaram ao Brasil no navio que trazia a princesa Leopoldina e sua comitiva, em 1817, após seu casamento com o príncipe Pedro de Alcântara.

Com a finalidade de comparar de que modo se produziram narrativas de gênero envolvendo os primeiros monarcas do Brasil nessas duas produções, partimos do levantamento de diálogos, elementos de caracterização dos personagens e aspectos ligados à produção. As narrativas construídas por meio desses elementos permitem compreender performances que associam Leopoldina e Pedro aos papéis sociais feminino e masculino. 


\section{Heroísmo e virtude em Independência ou Morte}

Nos dez primeiros minutos do filme Independência ou Morte, apresenta-se o protagonista, Dom Pedro I, em meio às relações familiares e às obrigações políticas impostas por sua posição. Filho mais velho do príncipe regente do Reino Unido de Portugal, Brasil e Algarves, Pedro deveria se preparar para assumir o trono que herdaria. A união com a austríaca Leopoldina de Habsburgo era um passo para sua inserção no mundo de funções públicas.

As primeiras cenas mostram Pedro sorridente chegando ao Palácio da Quinta da Boa Vista, até ouvir de seus pais que deveria se casar. Carlota Joaquina tem expressão severa. Dom João VI parece pouco interessado, agindo sobretudo para atender à esposa. Sua fala enérgica encerra a questão, deixando Pedro sem argumentos. Na sequência, o príncipe aguarda a chegada de Leopoldina. À medida em que ela se aproxima, as feições de Pedro passam da tensão ao encanto.

As interações dos personagens, além de suas caracterizações, ajudam a demarcar as posições que ocuparam na história e na trama. Pedro demonstra jovialidade, carisma e despreocupação; Leopoldina aparece séria e recatada. Na caraterização, a indumentária e a produção de maquiagem e cabelo seguem suas representações mais conhecidas. A Leopoldina de Kate Hansen se assemelha às imagens da imperatriz em ilustrações dispostas em museus e em livros históricos: cabelos louros e cacheados, pele e olhos claros. O uso de roupas em cores claras, adornos na cabeça e joias da realeza é elemento presente em boa parte de suas ilustrações.

A caracterização de Dom Pedro I também opta, como observa Fonseca (2018), pelo alinhamento a certos estereótipos, como as características de galanteador e popular. O personagem, identificado pelos cabelos e barba pretos, costeletas, vestes militares e ar sedutor, não por acaso, foi vivido por um galã.

Passadas as sequências iniciais, a trama se volta para a trajetória política de Dom Pedro I no Brasil. Após uma reunião familiar no Palácio da Quinta da Boa Vista, Leopoldina aconselha o marido a ajudar Dom João VI nas questões do governo, a situação política se mostrando instável. Em tom assertivo, a arquiduquesa afirma ser o Brasil seu e de Pedro, pois havia muito o que fazer pelo país. Aqui o filme inicia a representação da atuação política de Leopoldina, 
preparada durante anos de rígida educação na Casa dos Habsburgo, importante dinastia europeia na época.

Apesar de não ser considerada uma narrativa inovadora, Independência ou Morte demonstra a influência política da princesa, o que chama a atenção em uma produção do início da década de 1970. Nessa representação, a imperatriz se mostra segura e decidida, o que destoa das descrições que a resumem como esposa traída, melancólica e solitária. Sem se aprofundar em seus anseios e inquietações, o filme retrata uma Leopoldina com características de heroínas românticas: boa esposa, companheira, leal e adaptada às exigências da vida de princesa.

Em Independência ou Morte, a representação assume nuances tradicionais, semelhantes às narrativas dos livros de história do Brasil. Nesse percurso, constrói-se a imagem de Pedro I como herói da pátria em meio a outras figuras que participaram do cenário da Independência. O filme se alinha à necessidade da invenção de heróis que possam agregar valores que identifiquem os indivíduos de um grupo social a partir da exortação de suas virtudes individuais, como ensina Enders (2012). No filme, o engajamento crescente de Pedro com as questões políticas faz com que se apresente como alguém cuja dedicação ao Brasil gera a imagem de uma grande figura, um nome a ser reconhecido.

Ainda no filme, enquanto Dom Pedro circulava livremente pelas ruas do Rio de Janeiro, cumprimentando as pessoas, Dona Leopoldina só é vista nas dependências do Palácio ou em ambientes fechados. Constrói-se assim uma dicotomia fundamental para o desenrolar de seu relacionamento e dos fatos que marcaram suas vidas pessoais. O príncipe tinha liberdade para frequentar festas, andar pelas ruas e se encontrar com outras mulheres, enquanto sua esposa tinha circulação restrita, o que é descrito em relatos biográficos sobre Leopoldina. Retomando Perrot (1997), podemos analisar a narrativa produzida pelo filme a partir da demarcação dos espaços públicos nos quais Pedro transita e interage, e dos espaços privados e domésticos em que se encontram Leopoldina. A produção remete, novamente, às tradicionais condições de gênero homem x mulher encontradas nos relatos históricos.

Se Independência ou Morte apresenta os aspectos de heroísmo, virtude e virilidade em Dom Pedro I, Leopoldina desempenha os papéis de princesa, esposa e imperatriz com a altivez exigida por sua posição. É dessa maneira que ela reage após saber dos casos extraconjugais do marido. Alguns diálogos demonstram que não apenas Leopoldina estava ciente do que acontecia 
ao redor, como também procurava manter discrição e, seguindo as orientações de sua educação, sustentava a postura que julgava adequada para proteger a imagem da família e do império recém instituído no Brasil. Evitar um escândalo era fundamental. Leopoldina demonstra características usualmente associadas às mulheres, como a capacidade de se sacrificar e de se doar. Ela encarna, portanto, um dos arquétipos de representação feminina típicos da cinematografia nacional, o da jovem virtuosa (GUBERNIKOFF, 2009).

Com foco na apresentação dos acontecimentos políticos que levaram à independência do Brasil, Independência ou Morte não atribui destaque à união de Pedro e Leopoldina. Na trama, ele é o protagonista de todo o processo, enquanto a ela cabe um papel de apoio. Não se encontram no filme aspectos ligados à atuação caritativa de Leopoldina junto à população do Rio de Janeiro, tampouco os últimos acontecimentos de sua trajetória, até sua morte precoce. Ao voltar para Portugal, após abdicar do trono brasileiro, Pedro I já está acompanhado de sua segunda esposa - Dona Amélia de Leuchtenberg - sem que houvesse espaço para que se desenvolvesse, em cena, esse percurso. Apresenta-se no filme uma perspectiva essencialmente masculina do poder, na qual a presença das mulheres se dá em condição coadjuvante.

\section{Romantismo e pautas contemporâneas em Novo Mundo}

Sem camisa, fugindo pela janela do quarto em razão da chegada repentina do marido de sua amante e partindo a galope ao encontro de seus pais em uma igreja: assim é apresentado o personagem Pedro de Alcântara, futuro Dom Pedro I, na primeira cena da novela Novo Mundo, exibida pela Rede Globo entre março e setembro de 2017.

Os protagonistas, personagens fictícios, estavam envolvidos com situações e pessoas que participaram dos fatos e das decisões ocorridas durante o período que antecedeu a Independência do Brasil. Na produção, Anna era a professora de português da arquiduquesa Leopoldina (vivida por Letícia Colin), e Joaquim chegou a trabalhar como segurança particular de Dom Pedro I (o ator Caio Castro), de quem descobriu, ao longo da trama, ser irmão por parte de pai. Diferente do que acontece no filme Independência ou Morte, em Novo Mundo a união entre Pedro e Leopoldina ocupa espaço significativo ao longo da trama.

A arquiduquesa Leopoldina de Habsburgo, como relatam algumas biografias, dava tons romanceados a seus sonhos com o marido, que ainda iria conhecer, e também com aquela que 
seria sua pátria daquele momento em diante (OBERACKER JR., 1973). Em Novo Mundo, a representação da princesa seguiu essa orientação romântica durante a trama. Na caracterização da personagem, representações conhecidas da imperatriz se somaram às mudanças ocorridas durante sua trajetória no Brasil, influenciando tanto a escolha de figurinos quanto a produção da maquiagem e do cabelo da atriz. Convém lembrar que Leopoldina e Pedro não conheceram a fotografia e, portanto, as imagens que se têm dos primeiros monarcas do Brasil resultam de registros iconográficos realizados por encomenda da própria família real portuguesa ou por iniciativa de artistas como Jean-Baptiste Debret e Simplício Rodrigues de Sá (REIS; SIQUEIRA; MENDES, 2018).

A princesa radiante e cheia de esperanças do início da trama é caracterizada em trajes elaborados, de acordo com ilustrações da época em que Leopoldina se casou. Da mesma forma, penteados e adornos refletem uma representação conforme a posição de uma arquiduquesa da Casa dos Habsburgo, recém-casada com o príncipe herdeiro dos Bragança. No início de Novo Mundo, Leopoldina transparece alegria em sorrisos e em falas eufóricas. Após sofrer decepções devido às traições do marido e às dificuldades de se adaptar ao Brasil, a princesa surge em meados da trama com ares abatidos. Pouca maquiagem, cabelos desgrenhados e figurinos mais simples conotam essas mudanças.

Dom Pedro surge novamente em Novo Mundo como galã. O ator Caio Castro deu vida ao primeiro imperador do Brasil, cuja caracterização estava alinhada às representações que o descreveram como belo e conquistador. A beleza do príncipe teria sido comentada entre membros da Corte austríaca quando a arquiduquesa recebeu de presente o retrato de Pedro, após terem sido acertados os termos de seu casamento. Elogios aos "cachos de cabelos pretos que lhe caem na testa", às "sobrancelhas elegantemente arqueadas" e ao brilho dos olhos do príncipe foram anotados pela noiva em seu diário, tendo ela se gabado pelo fato de "todos invejarem seu príncipe" (KAISER, 2005, p. 52).

Se entendemos, como Corbin, Courtine e Vigarello (2011), que as performances de virilidade estão em permanente revisão, o mesmo acontece com os ideários em torno de personalidades da realeza, como Dom Pedro. Ao se alinharem aos relatos da historiografia tradicional, as representações contemporâneas sobre o monarca em canais midiáticos procuram apresentar atualizações dos ideais de virilidade, beleza masculina, liderança e altivez, aspectos 
comumente associados à figura do imperador. É nesse contexto que se construiu a caracterização do personagem em Novo Mundo.

A representação de Dom Pedro I na novela apresenta, dentro dos paradigmas atuais, a reprodução discursiva tradicional do príncipe galante, heroico e temperamental, imortalizado em contos de fadas. Trata-se, portanto, de uma caracterização que contribui para a legitimação de determinados ideários de masculinidade já reconhecidos coletivamente.

O aspecto romântico é o elemento de convergência entre as representações de Pedro e Leopoldina na novela. Se a princesa se mostra sonhadora e apaixonada, seu marido prepara surpresas e compõe canções para a esposa. Nos capítulos 129 e 130 da trama, ambos estão em crise no casamento, após uma série de desentendimentos e frustrações. Nesses dois capítulos é retratada uma tentativa de reconciliação entre Pedro e sua esposa, diante das traições do príncipe com Domitila de Castro Canto e Melo, a Marquesa de Santos.

A situação representada nesses dois capítulos não encontra paralelo nos registros históricos - por mais que Leopoldina tivesse ciência das traições do marido e se ressentisse por isso, os relatos históricos não apresentam sinais de que Pedro se esforçasse para criar momentos de surpresas e súplicas por reconciliação. A construção midiática da reconciliação ocorre de acordo com paradigmas contemporâneos de relacionamentos amorosos, determinando uma forma de "presentificação" do passado, a fim de que esse passado seja assimilado pela audiência. Na mesma perspectiva, as emoções manifestadas pelos personagens transmitem o dilema da traição conjugal em moldes contemporâneos: a postura arrependida de Pedro e a tristeza de Leopoldina não diferem de expressões emocionais de obras de ficção atuais.

Ainda buscando atualizar o contexto da trama de Novo Mundo, os autores colocam em pauta, em alguns momentos, assuntos e interesses que não correspondem à época representada. É nessa esfera que se situam questões como o estabelecimento de reservas indígenas, a abolição da escravatura e até mesmo a condição feminina na sociedade.

Mulheres que fazem parte de outros núcleos da novela, como uma atriz de teatro e a dona de uma taverna apresentam atitudes que destoam dos padrões de conduta feminina no início do século XIX no Brasil. A primeira cria seu filho sozinha e busca sucesso na profissão, enquanto a segunda, já ao final da trama, se interessa e se envolve com a política local. Da 
mesma forma, a protagonista (Anna) se separa de seu marido e se une a Joaquim, com quem já havia tido uma filha. Ao mesmo tempo, ela realiza o sonho de se tornar escritora.

Essas mulheres são personagens de ficção, ao contrário de Dona Leopoldina. No caso da primeira imperatriz do Brasil, a historiografia persiste como sustentação da construção da personagem, embora se encontrem, em Novo Mundo, diferenças em comparação às narrativas de Independência ou Morte. Na produção mais recente, Leopoldina transita com mais frequência na vida e em ambientes públicos: ela aparece na função de regente do país, participa de reuniões com ministros e interage com personagens de diversos núcleos. A atuação política de Leopoldina não se restringe, portanto, à influência exercida sobre o marido nos limites de seus aposentos privados. Como princesa e eventual regente do Brasil, sua figura é exaltada e suas possibilidades de interação social são mais amplas em comparação com outras mulheres.

Na novela, as memórias midiatizadas de Pedro e Leopoldina conduziram a uma trama romântica clássica, em que princesa e príncipe se apaixonam, sofrem decepções, enfrentam desafios, demonstram suas virtudes e, ao final, são recompensados pelo amor correspondido e pela promessa de felicidade duradoura. Pedro e Leopoldina desempenham os paradigmas ligados aos gêneros masculino e feminino. Ele, arrojado e carismático, mostra-se prisioneiro na posição de homem casado, enquanto ela, dedicada e amorosa, demonstra resiliência e esperança na união conjugal. O final feliz contribui para que se estabeleça a percepção de que os conflitos são, enfim, neutralizados pelo amor.

\section{Considerações finais}

Por meio das mídias circulam narrativas sobre os nomes do passado, que concorrem para a construção de representações alinhadas às diferentes visões de mundo desenvolvidas ao longo do tempo. Nesse processo, cada representação é a oportunidade de um retrato diferente, pintado em outras cores, apresentando aspectos nem sempre enfatizados pela representação anterior. Dessa forma se produzem, de tempos em tempos, as representações midiáticas de Dom Pedro I e Dona Leopoldina. Em Independência ou Morte e Novo Mundo encontramos semelhanças e diferenças em torno dessas representações.

Enquanto no filme se destaca a dimensão política da união dos dois monarcas, na telenovela seus papéis sociais ganham complexidade, abrindo espaço para suas interações 
particulares. Em Novo Mundo, por vezes o relacionamento entre Leopoldina e Pedro é tão destacado quanto o romance dos dois protagonistas. Por esse motivo, puderam ser colocadas em cena situações que retratam aspectos íntimos de suas performances feminina e masculina. Se Dom Pedro é apresentado como um herói atormentado por inseguranças do jovem rapaz que ele era, Leopoldina se mostra ao mesmo tempo firme e delicada, sensível a assuntos pessoais, familiares e políticos.

As duas produções se mostram diferentes no tocante à atuação de Leopoldina e Pedro nas esferas pública e privada. É possível identificar dois diferentes alinhamentos narrativos nas obras analisadas: Independência ou Morte se constrói com bastante fidelidade aos relatos históricos tradicionais, incluindo o posicionamento conferido a homens e mulheres em meio aos "grandes feitos" da história. A partir das discussões de Perrot (1997), compreendemos no filme a nítida demarcação do protagonismo masculino na esfera pública e da restrição da atuação feminina nos ambientes privados.

Em Novo Mundo há a tentativa de inserir questões atuais no contexto histórico que serve como pano de fundo para o desenvolvimento da trama. Não somente as condições de gênero se encaixam nesse espectro, como também a própria romantização do relacionamento de Pedro e Leopoldina. Convém destacar que, como afirma Solnon (2012, p. 13), no início do século XIX, o "amor romântico" não era a tônica das uniões monárquicas, determinadas por alianças e interesses, sobretudo políticos.

Tanto Novo Mundo quanto Independência ou Morte são produtos de suas épocas, retratando paradigmas e pautas sociais circulantes. Ao compararmos o modo como as duas obras representam performances de gênero de Dona Leopoldina e Dom Pedro I, observamos que as diferenças estão relacionadas às mudanças que gradativamente se constroem na forma como se situam socialmente homens e mulheres no Brasil. A imagem midiatizada de Dom Pedro encontra paralelos na mesma cultura conservadora que valoriza a masculinidade dominadora, predominante nas esferas de poder e permissiva quando se trata do próprio comportamento nas questões privadas.

Performando o feminino e o masculino, Leopoldina e Pedro apresentam uma ideia de Brasil ancorada no binarismo heteronormativo homem $\mathrm{x}$ mulher que não contempla a 
complexidade de manifestações e papéis de gênero possíveis, mas que ainda prevalece em discursos e percepções sobre o país.

\section{Referências}

ASSOCIAÇÃO NACIONAL DE TRAVESTIS E TRANSEXUAIS. [S.d.]. Disponível em : https://antrabrasil.org/assassinatos/. Acesso em: 23 fev. 2020.

BEAUVOIR, Simone de. Le deuxième sexe. Paris: Gallimard, 1949. Tomes I et II.

BUTLER, Judith. Gender trouble. Nova Iorque: Routledge Press, 1999.

CORBIN, Alain; COURTINE, Jean-Jacques; VIGARELLO, Georges. Histoire de la virilité. Paris: Seuil, 2011. Tome 1: L'invention de la virilité de l'Antiquité aux lumières.

DECLARACÃO de Damares Alves sobre cores de roupas de meninos e de meninas provoca polêmica. Jornal Nacional, 3 jan. 2019. Disponível em: https://g1.globo.com/jornalnacional/noticia/2019/01/03/video-de-ministra-sobre-cores-para-criancas-repercute-nasredes.ghtml. Acesso em: 23 fev. 2020.

ENDERS, Armelle. Plutarque au Brésil: passé, héros et politique (1822-1922). Paris: Les Indes Savantes, 2012.

FONSECA, Vitória Azevedo da. Quando as contradições são conciliadas e a história "oficial" vai além do controle de Estado. Temática, v. 12, n. 03, NAMID/UFPB, p. 29-45, mar. 2016. Disponível em: https://periodicos.ufpb.br/ojs2/index.php/tematica/article/view/28215. Acesso em: 23 fev. 2020.

FONSECA, Vitória Azevedo da. A monarquia no cinema brasileiro: metodologia e análise de filmes históricos. Jundiaí: Paco, 2018.

GUBERNIKOFF, Giselle. A imagem: representação da mulher no cinema. Conexão Comunicação e Cultura, Caxias do Sul, v. 8, n. 15, p. 65-77, jan./jun. 2009. Disponível em: http://www.ucs.br/etc/revistas/index.php/conexao/article/view/113/104. Acesso em: 23 fev. 2020.

HAMBURGER, Esther. Telenovelas e interpretações do Brasil. Lua Nova, São Paulo, n. 82, p. 61-86, 2011.

JAKUBASZKO, Daniela. A representação das masculinidades na telenovela: entre o machismo, o modelo ideal e a ruptura com o modelo hegemônico da masculinidade. In: CONGRESO DA ASSOCIAÇÃO LATINOAMERICANA DE INVESTIGADORES EM COMUNICAÇÃO-ALAIC, 12.,, 2014, Lima, Peru. Anais [...]. Disponível em: 
http://congreso.pucp.edu.pe/alaic2014/wp-content/uploads/2014/10/GI3-DanielaJakubaszko.pdf. Acesso em: 12 nov. 2020.

KAISER, Gloria. Um diário imperial: Leopoldina, Princesa da Áustria, Imperatriz do Brasil, de $1^{\circ}$ de dezembro de 1814 a 5 de novembro de 1817. Rio de Janeiro: Reler, 2005.

LANDSBERG, Alison. Engaging the past: mass culture and the production of historical knowledge. Nova Iorque: Columbia University Press, 2015.

LAURETIS, Teresa de. A tecnologia do gênero. In: HOLLANDA, Heloisa Buarque de (org.). Tendências e impasses: o feminismo como crítica da cultura. Rio de Janeiro: Rocco, 1994. p. 206-242.

LOPES, Camilla Bastos; GROSSI, Fabiana Regina Silva. O primeiro-damismo na assistência social: uma análise crítica. In: CONGRESSO DE INICIAÇÃO CIENTÍFICA DA FASB, 17. Barreiras, Bahia, 2019. Anais [..]. Disponível em: http://www.fasb.edu.br/revista/index.php/cic/article/view/482/421. Acesso em: 12 nov. 2020.

MACHADO, Sandra de Souza. Estereótipos de gênero e papéis modelo: \#Mais Mulheres Maravilha no Cinema. Revista Observatório, Palmas, v. 3, n. 6, 2017. Disponível em: https://sistemas.uft.edu.br/periodicos/index.php/observatorio/article/view/4161/11656. Acesso em: 23 fev. 2020.

MARCELO, Felipe Cavalcante. As contradições do imperador: a monumentalização do passado em Independência ou Morte (1972). O Olho da História, n. 17, Salvador, dez. 2011. Disponível em: http://oolhodahistoria.ufba.br/wp-content/uploads/2016/03/felipe-1.pdf. Acesso em: 23 fev. 2020.

MENDES, Mônica; SIQUEIRA, Denise da Costa Oliveira. Protagonismo feminino em desenhos animados: gênero e representações no entretenimento audiovisual. Mídia e cotidiano. v. $12, \quad$ p. $125-144, \quad 2018 . \quad$ Disponível em: https://periodicos.uff.br/midiaecotidiano/article/view/10065. Acesso em: 23 fev. 2020.

NOVO Mundo: capítulo 113 da novela, terça, $1^{\circ}$ de agosto, na Globo. Disponível em: https://www.youtube.com/watch?v=-TRQJ2HSRUs. 01 ago. 2017. Acesso em: 14 jul. 2020.

OBERACKER JR., Carlos H. A imperatriz Leopoldina: sua vida e sua época: ensaio de uma biografia. Rio de Janeiro: Conselho Federal de Cultura e IHGB, 1973.

PERROT, Michelle. Práticas da memória feminina. Revista Brasileira de História, São Paulo, v. 9, n. 18, p. 9-18, ago./set. 1989.

PERROT, Michelle. Escrever uma história das mulheres: relato de uma experiência. Cadernos
Pagu,
$\mathrm{n}$.
4 ,
p. 9-28,
1995.
Disponível
em: 
https://periodicos.sbu.unicamp.br/ojs/index.php/cadpagu/article/view/1733. Acesso em: 23 fev. 2020.

PERROT, Michelle. Femmes publiques. Paris: Les Éditions Textuel, 1997.

REIS, Jarlene Rodrigues; SIQUEIRA, Euler. D.; MENDES, Thaynan B. Histórias de príncipe e princesa: memórias midiáticas da união entre Dona Leopoldina e Dom Pedro I na telenovela Novo mundo. Memorare, v. 5, p. 292-306, 2018. Disponível em: https://portaldeperiodicos.unisul.br/index.php/memorare_grupep/article/view/7348. Acesso em: 23 fev. 2020.

RIBEIRO, Arilda Inês Miranda. A contribuição da imperatriz Leopoldina à formação cultural brasileira (1817-1826). ANPUH-SIMPÓSIO NACIONAL DE HISTÓRIA, 23., 2005, Londrina. Anais [...]. Disponível em: http://snh2015.anpuh.org/resources/anais/anpuhnacional/S.23/ANPUH.S23.0144.pdf. Acesso em: 23 fev. 2020.

RIBEIRO, Joyce. Feminicídio está entre os crimes que aumentaram no Brasil em 2019. R7. Retrospectiva, 20 dez. 2019. Disponível em: http://www.r7.com/retrospectiva2019/fotos/feminicidio-esta-entre-os-crimes-que-aumentaram-no-brasil-em-2019-

20122019\#!/foto/1. Acesso em: Acesso em: 23 fev. 2020.

SCOTT, Joan. Gender: a useful category of historical analyses. The American Historical Review, v. 91, Issue 5, p. 1053-1075, 1986.

SIQUEIRA, Denise da Costa Oliveira. Divas: corpo, performance e gênero em videoclipes. In: CHIARA, Ana et al (orgs). Bioescritas, biopoéticas: corpo, memória e arquivos. Porto Alegre: Sulina, 2017. p. 318-334.

SOLNON, Jean-François. Les couples royaux dans l'histoire: le pouvoir à quatre mains. Paris: Perrin, 2012.

TAZI, Nadia. Le genre intraitable: politiques de la virilité dans le monde musulman. Arles: Actes Sud, 2018.

TORRES, Iraildes Caldas. As primeiras-damas e a assistência social: relações de gênero e poder. São Paulo: Cortez, 2002.

Submetido em: 12.11.2020.

Aprovado em: 28.12.2021. 